\title{
PRIMARY LYMPHOMA OF THE BLADDER
}

\author{
KATIA R. M. LEITE, HOMERO BRUSCHINI, LUIZ H. CAMARA-LOPES
}

Laboratory of Surgical and Molecular Pathology, Syrian Lebanese Hospital, São Paulo, SP, Brazil

\begin{abstract}
Primary lymphomas of bladder are rare, have a good prognosis and present good response to chemotherapy. We report a case of primary lymphoma affecting the bladder of an 89-year old female patient who, despite full response to chemotherapy, presented recurrence and death 1 year after concluding the treatment. The authors emphasize the differential diagnosis due to the great differences concerning prognosis and therapeutic approach.
\end{abstract}

Key words: bladder; neoplasms; lymphoma; treatment Int Braz J Urol. 2004; 30: 37-9

\section{INTRODUCTION}

Primary lymphomas of bladder are rare, representing less than $1 \%$ of vesical tumors and $0.2 \%$ of extranodal lymphomas. Among the differential diagnoses are the small cell carcinoma and the lymphoepithelioma-like carcinoma, in addition to rhabdomyosarcoma. The distinction between these pathologies is fundamental, since their prognosis and treatment are quite distinct. The authors present a case of primary lymphoma of bladder and discuss the differential diagnoses.

\section{CASE REPORT}

A female, Caucasian, 89 years old patient, presented complaints of urinary obstruction for 2 weeks in length. As morbid antecedents, she had undergone surgery for resection of an invasive breast ductal carcinoma of $1.6 \mathrm{~cm}$, without lymph nodal involvement 3 years earlier. There was recurrence of the breast neoplasia in skin 2 years after surgical treatment when she underwent radiotherapy.

The magnetic resonance imaging showed a diffuse thickening of the vesical wall involving the floor mainly, and extending to the posterior wall (Figure-1).

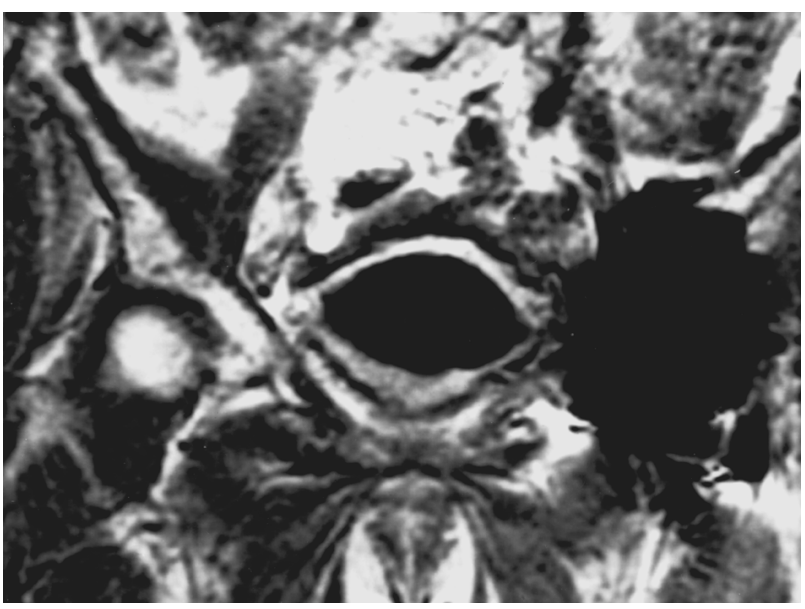

Figure 1 - Magnetic resonance imaging, T1-weighted sequence showing thickening of vesical wall affecting the trigone, with extension to the posterior wall and right lateral wall. 

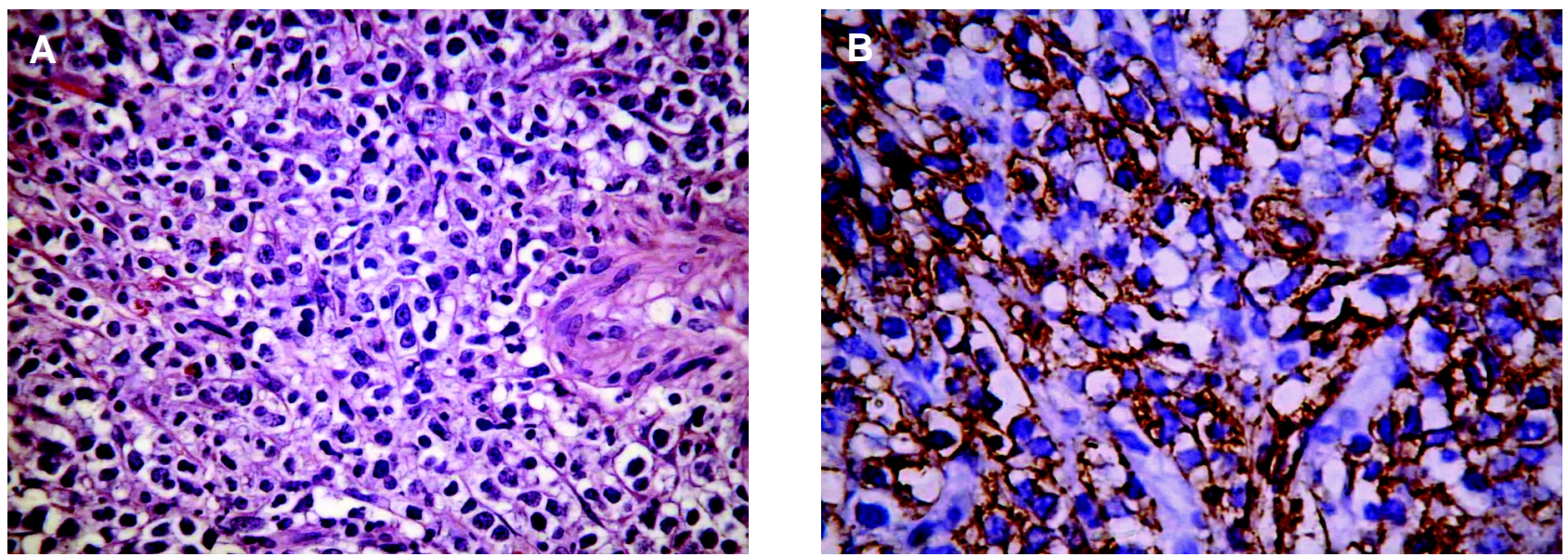

Figure 2 - A ) Photomicrography showing a diffuse large cell lymphoma infiltrating the vesical wall. B) Immunohistochemical reaction with anti-CD20 antibody, marker for B-lymphoid cells.

The vesical tumor was resected via transurethral and the pathological diagnosis was diffuse large cell lymphoma extensively infiltrating the vesical wall (Figure-2, A). The immunohistochemical analysis showed positivity to Leukocyte Common Antigen (LCA-CD45) and CD20, characterizing a B cell-derived lymphoma (Figure-2, B). Anti-cytokeratin antibodies showed complete negativity, discarding the possibility of carcinoma. Additionally, a clonality study was performed, assessing the rearrangement of the immunoglobulin heavy chain $(\operatorname{IgH})$, by polymerase chain reaction, which revealed a monoclonal pattern, diagnostic for lymphoma.

The patient underwent 6 CHOP cycles (cyclophosphamide, doxorubicin, vincristine and prednisone), with full response, and total relief of symptoms. One year after the conclusion of treatment there was recurrence of the lymphoma as a mass in the retroperitoneum as well as in the hepatic hilum, which caused obstruction of biliary tract, liver failure and death.

\section{DISCUSSION}

The bladder is secondarily involved by terminal lymphomas in 15 to $20 \%$ of cases, with the primary lymphoma of bladder being quite rare, representing less than $1 \%$ of vesical tumors and $0.2 \%$ of extranodal lymphomas. In 40 years, there have been
75 reports, with the largest casuistry being the one by Ohsawa et al. who in 1993 described 3 new cases and reviewed 27 cases published in the literature (1). Primary lymphoma of the bladder affects 6.5 times more women, with a mean age on diagnosis of 64 years ranging from 20 to 85 years. They are usually related to repeated cystitis and present as a solitary tumoral mass. The most common symptom is hematuria, followed by dysuria and nocturia. The great majority of lymphomas are non-Hodgkin originating from B cells, with $30 \%$ being diffuse large cell lymphomas. The second most common lymphoma is that with origin from mucosa-associated lymphoid tissue (MALT), with Burkitt and plasmocytoid lymphomas being described as well. The treatment is the same as with nodal lymphomas, with the great majority being treated with CHOP. Radiotherapy can be indicated eventually. The role of surgery is debated, since the diagnosis is usually made following endoscopic resection of the lesion. The response to treatment is generally rapid and cure indexes are high, between 82 and $89 \%$ for diffuse large cell lymphomas and $100 \%$ for MALT lymphomas.

The differential diagnosis is fundamentally important, especially for small cell carcinomas. Those are equally rare tumors, corresponding to 0.5 to $1 \%$ of primary tumors of bladder and up to 2001, 134 cases had been reported in the literature (2). They affect 4 times more men and the mean age at diagnosis 
is 66 years. In $50 \%$ of cases, the small cell pattern is associated with the conventional transitional cell carcinoma, suggesting a metaplastic process. They are aggressive tumors, and in $56 \%$ of cases, the patients present metastases at the diagnosis. The mortality is almost $70 \%$ usually in the first year. The diagnosis is basically morphologic, with tumors being invariably positive for anti-cytokeratin antibodies, with expression of neuron-specific enolase in $86 \%$ and chromogranin A in $30 \%$. Better cure chances are reported with surgery and adjuvant chemotherapy with regimens containing cisplatin.

The lymphoepithelioma-like carcinoma is extremely rare, with 14 cases described. They are morphologically characterized by large cells clusters with syncitial aspect in midst of an exuberant lymphocytic infiltrate. They are constantly positive to anti-cytokeratin antibody, and behave like usual transitional cell carcinomas in the same stage (3).

At a younger age range, one must consider the diagnosis of rhabdomyosarcoma, which represents $6 \%$ of tumors in children under 15 years old, with $20 \%$ affecting the urogenital tract. In addition to the bladder, it involves the prostate, paratesticular region and vagina. The morphologic diagnosis can be made through visualization of transverse striations in rhabdomyoblasts that can be confirmed with the use of anti-desmin antibody, positive in $100 \%$ of cases. Currently, an aggressive therapeutic approach has resulted in the survival of 70 to $73 \%$ of patients with primary tumors of bladder and prostate. The most important prognostic factors are the histological type and the macroscopic aspect. The botryoid type has the best prognosis, followed by the embryonal rhabdomyosarcoma, with the alveolar type being quite aggressive. The presentation as a single polypoid mass has also a better outcome when compared with tumors with diffuse aspect (4).

\section{REFERENCES}

1. Ohsawa M, Aozasa K, Horiuchi K, Kanamaru A: Malignant lymphoma of bladder. Cancer. 1993; 72: 1969-74.

2. Trias I, Algaba F, Condom E, Español I, Segui J, Orsola I, et al.: Small cell carcinoma of the urinary bladder. Eur Urol. 2001; 39: 85-90.

3. Holmang S, Borghede G, Johansson SL: Bladder carcinoma with lymphoepithelioma-like differentiation. J Urol. 1998; 159: 779-82.

4. Leuschner I, Harms D, Mattke A, Koscielniak E, Treuner J: Rhabdomyosarcoma of the urinary bladder and vagina. Am J Surg Pathol. 2001; 25: 856-64.
Received: October 30, 2003

Accepted: December 12, 2003

\author{
Correspondence address: \\ Dr. Katia Ramos Moreira Leite \\ Rua Adma Jafet, 91 \\ São Paulo, SP, 01308-050, Brazil \\ Fax: + 5511 3231-2249 \\ E-mail:katiaramos@uol.com.br
}

